\title{
ZNAČAJ PROUČAVANJA PROFESIONALNOG IDENTITETA ŠKOLSKOG PEDAGOGA**
}

Proučavanje prirode i strukture profesionalnog identiteta postaje veoma aktuelno područje istraživanja u okviru različitih profesija društveno-humanističkog usmerenja, posebno kada je reč o tzv. pomagačkim profesijama, usled težnje ka njihovom unapređivanju, razvoju i afirmaciji. Okvir za razumevanje i proučavanje ovog fenomena jeste teorija socijalnog identiteta. Prema ovoj teoriji profesionalni identitet je sastavni deo self-koncepta pojedinca i predstavlja deo šireg socijalnog identiteta koji odgovara na pitanja o doprinosu i značaju koje profesionalno delovanje pojedinca ima u društvu. $U$ tom smislu profesija pedagoga, koja takođe spada u pomagačke profesije, predstavlja veoma inspirativno polje za proučavanje konstrukta profesionalnog identiteta, pri čemu se naglašava da sastavne komponente konstrukta, kao i indikatori koji utiču na njegovo razvijanje, umnogome zavise od konteksta u kom pedagog obavlja svoju delatnost. Imajući u vidu specifičnost školskog konteksta, u ovom radu se ističe potreba proučavanja brojnih (kako ličnih, tako i kontekstualnih) faktora koji determinišu razvoj profesionalnog identiteta školskog pedagoga. Posebno se apostrofiraju značaj i potreba empirijskog istraživanja ove tematike, jer identifikovanje faktora koji doprinose razvoju jasno izraženog profesionalnog identiteta može predstavljati značajan resurs za unapređivanje profesionalnog delovanja pedagoga, a samim tim i za unapređivanje rada škole kao institucije.

Ključne reči: Profesionalni identitet, školski pedagog, teorija socijalnog identiteta, samoefikasnost, samopoštovanje.

* senkaslijepcevic@ff.uns.ac.rs

** Rad je nastao u okviru projekata Pedagoški pluralizam kao osnova strategije obrazovanja (179036) i Digitalne medijske tehnologije i društveno-obrazovne promene (47020) čjiu realizaciju finansira Ministarstvo prosvete, nauke i tehnološkog razvoja Republike Srbije. 


\section{UVOD}

Proučavanje i razmatranje konstrukta profesionalni identitet postaje predmet istraživanja $\mathrm{u}$ društveno-humanističkim naukama poslednjih nekoliko decenija. Posebno interesovanje za ovu tematiku primetno je u okviru tzv. pomagačkih profesija koje su još uvek u procesu razvoja i afirmacije, a čija je delatnost usmerena na brigu o drugima, odnosno na pružanje neposredne ili posredne pomoći pojedincu, manjoj ili većoj grupi. U tom smislu profesija pedagoga predstavlja veoma inspirativno polje za proučavanje ovog konstrukta, pri čemu je bitno naglasiti da sastavne komponente i indikatori koji utiču na njegovo razvijanje umnogome zavise od konteksta u kom pedagog obavlja svoju delatnost. Polazeći od teorije socijalnog identiteta, profesionalni identitet, kao deo socijalnog identiteta, moguće je razumeti kao proces koji podrazumeva stalno menjanje, interpretiranje i reinterpretiranje iskustava koje pojedinac ima u socijalnoj sredini, a koje su u vezi sa njegovom profesijom. Pored određenih ličnih karakteristika, veliki uticaj na razvoj profesionalnog identiteta imaju specifičnosti profesionalnog i šireg društvenog konteksta (institucionalni i vaninstitucionalni faktori). Shodno tome brojni istraživači u svetu svoju pažnju usmeravaju ka istraživanju profesionalnog identiteta stručnih saradnika u školama, polazeći od opštih karakteristika pedagoške profesije, specifičnosti školskog konteksta, kao i od širih društvenih faktora koji utiču na obrazovno-vaspitni sistem i školstvo.

Činjenica je da istraživanja profesionalnog identiteta stučnjaka koji svoju delatnost obavljaju u školi nisu baš česta, posebno kada je reč o profesionalnom identitetu školskih pedagoga. Takvo stanje je verovatno posledica teškoća u jasnom određenju komponenti profesionalnog identiteta, te činjenice da su neke karakteristike školskog konteksta koje oblikuju profesionalni identitet teško merljive. Međutim, to ne umanjuje značaj i potrebu takvih istraživanja. Štaviše, u uslovima promenljivog obrazovnog konteksta potreba za proučavanjem ove tematike dobija na značaju, jer nejasnoće u percepciji sopstvenog profesionalnog identiteta mogu da umanje sposobnost pedagoga da adekvatno obavlja svoje profesionalne zadatke i da postupa etički u svom radu (Gibson, Dollarhide \& Moss, 2010). Takođe, stanje nedovoljno jasno izraženog profesionalnog identiteta školskog pedagoga može za posledicu da ima to što relevantni subjekti u školama ne prepoznaju razliku između uloge pedagoga i drugih profesionalaca zaposlenih u obrazovno-vaspitnoj instituciji (Woo, Lu \& Bang, 2018). Stoga je cilj ovog rada da, polazeći od teorije socijalnog identiteta i analize ključnih komponenti i indikatora profesionalnog identiteta, ukaže na važnost bavljenja ovim pitanjima za afirmaciju, napredovanje i razvoj profesije pedagoga u kontekstu savremene škole. 


\section{TEORIJA SOCIJALNOG IDENTITETA KAO OKVIR ZA RAZUMEVANJE KONSTRUKTA PROFESIONALNI IDENTITET}

Identiteti predstavljaju osobine i karakteristike ličnosti, različite uloge, relacije sa drugima i pripadnost društvenim grupama koje definišu osobu kao takvu. Oni nam služe za snalaženje u svetu i razumevanje sveta oko nas i sačinjavaju jedinstveni self-koncept. Self (predstava o sebi) se koristi kao okvir za pridavanje smisla okruženju i donošenje odluka o našem delovanju. Pomoću selfa, tj. osećaja da poznajemo sebe, percipiramo socijalnu sredinu i upravljamo sopstvenim ponašanjem (Horowitz \& Bordens, 1995, Myers, 1996). Uobičajeno se govori o tri tipa selfa (predstave o sebi) - privatnom, javnom i kolektivnom - čija su zastupljenost i uticaj na self-koncept pojedinca različiti. Privatni self je predstava o sebi u okviru koje se nalaze naše privatne misli i procene o tome ko smo i kakvi smo. Javni self je ona predstava o sebi koju predstavljamo drugima i koji sadrži naše misli o tome kako nas bilo koji pojedinac iz populacije svih ljudi vidi. Kolektivni self je ona predstava o sebi koja reflektuje kako nas procenjuju nama značajni pojedinci, pripadnici grupa kojima i mi pripadamo (Horowitz \& Bordens, 1995). Određeni aspekti selfa služe kao motivacija za delovanje. Samim tim, predstava o sebi u datom trenutku upravlja reakcijama osobe na draži iz spoljašnje sredine. S druge strane, osećaj da poznajemo sebe implikuje postojanje određene stabilnosti u tom saznanju. Ipak, ne sme se zanemariti činjenica da identiteti predstavljaju dinamične i multidimenzionalne konstrukte koji se kontinuirano formiraju i reformiraju, prateći razvoj pojedinca tokom vremena i kroz interakcije sa drugima (Cooper \& Olson, 1996).

Teorijsko uporište o profesionalnom identitetu moguće je pronaći u teoriji socijalnog identiteta. Prema ovoj teoriji socijalni identitet je deo našeg selfkoncepta koji se formira iz same pripadnosti određenoj grupi (nacionalnoj, političkoj, profesionalnoj i radnoj), a potom i iz emocionalnog doživljaja i vrednosti vezanih za tu pripadnost (Tajfel, 1982). Drugim rečima, pojedinci definišu sebe, tj. sopstveni identitet, na osnovu odrednica i karakteristika koje odlikuju grupe kojima pripadaju (Brown, 2003). Pojedini autori (Bergami \& Bagozzi, 2000; Ellemers, Kortekaas \& Ouwerkerk 1999; Horowitz \& Bordens, 1995) izdvojili su tri komponente koje utiču na socijalni identitet pojedinca, a to su: kognitivna komponenta (saznanje, svest o pripadnosti određenoj grupi - samokategorizacija), evaluativna komponenta (pozitivne ili negativne vrednosti koje se vezuju za pripadnost određenoj grupi - kolektivno samopoštovanje) i emocionalna komponenta (osećaj emocionalne povezanosti sa grupom - afektivna posvećenost). Povezano sa istaknutim, važna je i teorija samokategorizacije koja direktno 
proizilazi iz ranih razmatranja pitanja socijalnog identiteta, što čini ove dve teorije usko povezanima. Socijalna kategorizacija povezuje opažene sličnosti posmatranih ljudi sa prototipom prosečnog pripadnika jedne grupe (Hogg \& Terry, 2001). Drugim rečima, pripadnost grupi dovodi do transformisanja selfa jer procesom samokategorizacije težimo da percepciju o sebi i naša ponašanja uskladimo sa prototipom predstavnika naše grupe. Razmatranje socijalnog identiteta uglavnom se zasnivalo na izučavanju grupa ljudi koji dele etničke, nacionalne, rodne, regionalne atribute, potom na izučavanju malih grupa blisko povezanih članova (npr. sportska ekipa) ili eksperimentalnih grupa ljudi. Nedovoljno je istraživanja koja su se usmeravala na izučavanje socijalnog identiteta u profesionalnom (organizacijskom) okruženju. Imajući u vidu koliko sopstvena profesija predstavlja relevantan okvir u kom pojedinac definiše sebe, te da pripadnost profesionalnoj grupi dovodi do asimilacije karakteristika te grupe sa self-konceptom, neophodno je fokusirati se na proučavanje ovog, užeg, dela socijalnog identiteta (Moore \& Hoffman, 1988) i to kroz specifikaciju ključnih komponenti i indikatora koji posredno ili neposredno oblikuju nivo izraženosti profesionalnog identiteta.

\section{POJAM I STRUKTURA PROFESIONALNOG IDENTITETA}

Tradicionalno poimanje profesionalnog identiteta opisuje ovaj pojam kao relativno stabilan i trajan skup karakteristika, uverenja, motiva i iskustava pojedinca, na osnovu kojih oni sebe definišu kao profesionalce (Ibarra, 1999). S druge strane, savremeno shvatanje pojedince stavlja u poziciju aktivnih konstruktora sopstvenog profesionalnog identiteta tako da i profesionalni identitet predstavlja dinamični, kontinuirani i aktivni proces konstrukcije koji podrazumeva trajno interpretiranje i reinterpretiranje iskustava pojedinca (Brott \& Myers, 1999; Goodson \& Cole, 1994; Lamote \& Engels, 2010; Rodgers \& Scott, 2008). Izgradnja profesionalnog identiteta predstavlja intrapersonalni i interpersonalni proces koji započinje još u periodu inicijalnog obrazovanja za određenu profesiju, a povezan je sa doživotnim profesionalnim usavršavanjem. Proces razvoja profesionalnog identiteta može da pomogne profesionalcu da odgovori na pitanja kao što su: Ko sam ja kao profesionalac?, Koje su moje uloge i koje su kompetencije neophodne za uspešno izvršavanje ovih uloga?, Zbog čega je moje profesionalno delovanje jedinstveno i vredno za društvenu zajednicu? itd. U relevantnoj literaturi moguće je pronaći različita određenja profesionalnog identiteta. To je self profesionalca koji se razvija kroz obavljanje profesionalnih uloga, integraciju personalnih atributa $i$ profesionalnog obrazovanja i koji se proverava kroz povratne informacije od strane značajnih drugih (Auxier, Hughes \& Kline, 2003; Chin Pei, 2014; Cooper \& Olson, 
1996; Gibson, et al., 2010; Woo, 2013). Osim toga profesionalni identitet se odnosi na sistem karakteristika, uverenja, vrednosti, motiva i iskustava na osnovu kojih pojedinci definišu sebe u profesionalnim ulogama (Ibarra, 1999), određuju svoje svrhe, ciljeve i vrednosti, pri čemu se ovaj sistem razvija kroz vreme (Woo, 2013).

Usled kompleksnosti konstrukta profesionalni identitet ne postoji saglasnost među autorima $u$ vezi sa strukturom tog konstrukta. Najčešće se izdvajaju tri opšte komponente: samoodređenje sebe kao profesionalca, integracija kompetencija i vrednosti ključnih za obavljanje profesionalne uloge, percepcija uloga i statusa profesije od strane značajnih drugih u profesionalnoj i široj društvenoj zajednici (Gibson, et al., 2010; Spasenović i Hebib, 2014). Ove komponente moguće je posmatrati i kao podidentitete profesionalnog identiteta (Lamote \& Engels, 2010). Drugi autori (Bergami \& Bagozzi, 2000) prilikom sagledavanja socijalnog identiteta u profesionalnom okruženju isticali su sledeće relevantne komponente: identifikaciju sa profesijom, posvećenost profesiji i samopouzdanje usled pripadnosti profesiji. Pojedini autori (Puglia, 2008; Woo \& Henfield, 2015; Woo, et al., 2018) govore o subdomenima profesionalnog identiteta: osnovno znanje o profesiji i razumevanje profesije, profesionalne kompetencije, stavovi prema profesiji, angažovanje u oblasti pedagoške profesije. Istaknuti subdomeni obuhvataju opšte komponente profesionalnog identiteta.

\section{FAKTORI I INDIKATORI PROFESIONALNOG IDENTITETA}

Profesionalni identitet se formira od početka pripreme za profesiju, ali se i kontinuirano konstruiše i rekonstruiše tokom čitave karijere. Reč je o višestrukom entitetu na čije oblikovanje utiču mnogi istorijski, sociološki, psihološki i kulturni faktori (Cooper \& Olson, 1996; Rodgers \& Scott, 2008). Pojedini istraživači (Lamote \& Engels, 2010) kao indikatore profesionalnog identiteta koji doprinose oblikovanju shvatanja pojedinca o tome ko je on kao profesionalac izdvajaju sledeće: promenljivu stvarnost profesija, orijentaciju prema cilju i zadacima profesionalnog delovanja, percipiranu samoefikasnost, posvećenost pozivu. Takođe, istraživanja su potvrdila da su percipirana samoefikasnost, osećaj samopoštovanja i samoaktualizovanost u profesionalnom delovanju značajno povezani sa izraženošću profesionalnog identiteta (Moore \& Hofman, 1988; Živković i Ranđelković, 2013), da socio-političke i kulturne vrednosti utiču na karijerne ciljeve i profesionalno delovanje profesionalaca u nastajanju (Watts, 1987), kao i da uvažavanje od strane pripadnika uže profesionalne i šire društvene zajednice značajno korelira sa jasnim i izraženim profesionalnim identitetom (Luke \& Goodrich, 2010). 
Kao posebno važan indikator profesionalnog identiteta izdvaja se percepcija samoefikasnosti, jer uverenje o sopstvenim sposobnostima za postizanje uspeha predstavlja determinantu mnogih procesa u profesionalnom delovanju, kao što su: nivo motivacije, zadovoljstvo poslom, sposobnost adaptacije, nivo stresa, posvećenost pozivu, psihološko i fiziološko zdravlje, težnja za promenom profesije, razvoj kompetencija (npr. multikulturalnih) (Bandura, 1997; Bodenhorn \& Skaggs, 2005; Chesnut \& Burley, 2015; Wang, Hall \& Rahimi, 2015). Za kompetentno funkcionisanje nisu dovoljna samo usvojena znanja, razvijene kompetencije i veštine iz određene oblasti, već i lična uverenja o sopstvenoj efikasnosti da ta znanja i kompetencije primenimo. U tom svetlu posmatrano, samoefikasnost predstavlja procenu pojedinca o sopstvenim sposobnostima da upotrebi veštine i kompetencije za uspešno rešavanje određenog problema ili za izvršavanje određenih zadataka (Bandura, 1986). Samim tim, procena samoefikasnosti nije usmerena na merenje kompetencija i veština koje pojedinac poseduje, već na sagledavanje uverenja pojedinca o tome šta on može da postigne sa onim čime raspolaže u različitim uslovima i situacijama (Bandura, 1997).

Još jedan relevantan indikator profesionalnog identiteta predstavlja samopoštovanje pojedinca. Nivo samopoštovanja, koji predstavlja pozitivnu evaluaciju pojedinca o sebi kao osobi/ličnosti, nesumnjivo je povezan sa selfkonceptom osobe, tačnije sa celinom kompleksnog, organizovanog i dinamičkog sistema naučenih verovanja, stavova i mišljenja koje pojedinac ima o sopstvenom postojanju (Purkey, 1988). Istraživanja su pokazala da pojedinci sa visokim samopoštovanjem češće vide sebe kao sposobne, značajne i vredne osobe nego pojedinci sa niskim samopoštovanjem (Cai, et al., 2015), da je visoko samopoštovanje povezano sa nižim rizikom od profesionalnog sagorevanja (Butler \& Constantine, 2005), kao i da je visina kolektivnog samopoštovanja profesionalaca pod uticajem društvenog statusa grupe (Ellemers, et al., 1999). Prema tome, moguće je zaključiti da je odnos između samopoštovanja i socijalnog, a samim tim i profesionalnog, identiteta dijalektički i multidimenzionalan. Koliki uticaj će pomenuti, ali i drugi, indikatori imati na profesionalni identitet zavisi od brojnih ličnih i kontekstualnih karakteristika, ali prevashodno od karakteristika same profesije o kojoj je reč.

\section{O POTREBI PROUČAVANJA PROFESIONALNOG IDENTITETA ŠKOLSKOG PEDAGOGA}

Profesija pedagoga se globalno nalazi među mlađim profesijama s obzirom na činjenicu da je od formiranja stručne službe u školama na našim prostorima i 
zapošljavanja prvih pedagoga - stručnih saradnika prošlo nešto više od pola veka. Do danas profesija pedagoga u školskom kontekstu prolazila je kroz različite faze menjanja - od osmišljavanja, afirmacije, deprofesionalizacije do reafirmacije profesije (Staničić, 2017; Trnavac, 1996). Usled toga i činjenice da između domena rada školskog pedagoga i drugih stručnih saradnika intenzivno dolazi do preklapanja (Popov i Spasenović, 2018) javlja se potreba za razmatranjem pitanja koja su vezana za utemeljenje i afirmaciju profesije pedagoga. Naime, preklapanje profesonalnih uloga stručnih saradnika različitih profila uslovljena je samom prirodom njihovog rada u kom je očekivano timsko delovanje. Međutim, takva isprepletanost dovodi do toga da je teško jasno sagledati granice profesionalnog delovanja konkretnog stručnog profila (Popov i Spasenović, 2018). Pravo na stručnu ekspertizu, što je jedna od osnovnih odrednica svake profesije, u slučaju (školskog) pedagoga predstavlja izazovan zahtev. Tako prema Zakonu o osnovama obrazovanja i vaspitanja (2017) poslove stručnog saradnika u školi mogu da obavljaju pedagog ili psiholog. U zavisnosti od veličine škole određuje se „broj izvršilaca na poslovima stručnog saradnika i to pedagoga ili psihologa, a zavisno od potreba škole i programa koji se ostvaruje to može da bude logoped, socijalni radnik, defektolog ili andragog“ (Pravilnik o kriterijumima i standardima za finansiranje ustanove koja obavlja delatnost osnovnog obrazovanja i vaspitanja 2016, član 10). Iako su poslovi školskog pedagoga definisani (Pravilnik o programu svih oblika rada stručnih saradnika, 2012), ovako postavljen Zakon omogućava supstituciju jednog stručnog saradnika drugim, što može da dovede do brisanja razlika između uloga, kompetencija i nadležnosti stručnih saradnika različitih profila. Ukoliko se pored svega navedenog uzmu u obzir i učestalost reformi obrazovnih sistema, zahtevi savremenog društvenog diskursa, procesi globalizacije, napredak nauke i tehnologije, kao i mnoge druge promene, evidentno je zbog čega je relevantno baviti se pitanjima profesionalnog identiteta školskih pedagoga. Samim tim nameće se neophodnost kontinuiranog traganja za odgovorima na pitanja koja mogu pomoći stvaranju jasnije slike o tome ko su školski pedagozi, koje je polje njihove specijalnosti, kao i koji su zadaci njihovog profesionalnog delovanja (Puglia, 2008).

Posmatrano sa aspekta pedagoške profesije, subdomeni (komponente) profesionalnog identiteta predstavljaju dobar referentni okvir u kom je moguće sagledati strukturu profesionalnog identiteta pedagoga. Za samoodređenje sebe kao profesionalca neophodno je da pedagog ima relevantna znanja o istorijskom razvoju svoje profesije, o etičkim standardima, profesionalnim mrežama, savremenim trendovima u pedagoškoj nauci i praksi, standardima i zahtevima koje je neophodno 
ispuniti kako bi (p)ostao pedagog (Woo, 2013). U okviru ovog subdomena polazi se od pretpostavke da bogato znanje o profesiji omogućava ostvarivanje jasnog uvida u to šta znači postati pripadnik pedagoške profesije (Emerson, 2010). O važnosti poznavanja istorijskog razvoja govorili su mnogi teoretičari (Emerson, 2010; Puglia, 2008; Woo 2013), što je istaknuto sledećim rečima: "Iako nasleđe nije sudbina, sudbina je delom zavisna od nasleđa" (Vacc \& Loesch, 1987: pp. 19). Dalje, veoma značajno za personalnu komponentu profesionalnog identiteta jesu i lična uverenja (stavovi) koja pedagozi imaju o sopstvenoj profesiji, pri čemu se posebno izdvajaju pozitivan lični odnos prema profesiji i osećaj ponosa zbog pripadnosti istoj. Važnost ispitivanja stavova o sopstvenoj profesiji isticana je i od strane autora sa naših prostora (Pavlović Breneselović, 2013; Šućur, 2011). Angažovanje pedagoga u oblasti pedagoške profesije, interakcije i umreženost, kao i profesionalne kompetencije mogu se podvesti pod komponentu integracija kompetencija i vrednosti za obavljanje profesionalne uloge. Pojedini autori (Luke \& Goodrich, 2010; Myers, Sweeney \& White, 2002) ukazuju na postojanje povezanosti između pripadnosti (članstva u) profesionalnim asocijacijama/udruženjima i razvoja profesionalnog identiteta, a posebno se ističe aktivnost na liderskim pozicijama koja doprinosi povezivanju teorije i prakse, razvijanju kompetencija i integrisanju vrednosti relevantnih za jednu profesiju (Luke \& Goodrich, 2010).

Sve navedeno ukazuje na potrebu proučavanja strukture i indikatora profesionalnog identiteta školskog pedagoga, posebno ako se ima u vidu činjenica da se profesija pedagoga, kako ističu neki autori (Staničić, 2017), nalazi u fazi reafirmacije. Značaj ovog pitanja potvrđuju i ranija istraživanja (Beijaard, Meijer \& Verloop 2004; Brott \& Myers, 1999; Moore \& Hofman, 1988; Skorikov \& Vondracek, 2011; Woo, et al., 2018) koja akcentuju da snažan profesionalni identitet može doprineti razvijanju osećaja ponosa i satisfakcije u vezi sa izabranom profesijom, boljem razumevanju sopstvenih profesionalnih uloga i odgovornosti, profesionalnom uspehu, socijalnoj adaptaciji i psihološkoj dobrobiti pojedinca.

\section{ZAKLJUČAK}

Neprepoznatljivost značaja profesije, nejasna slika o ulogama i nadležnostima profesije, kao i nezainteresovanost donosioca odluka za pitanja relevantna za unapređenje pozicije profesionalaca predstavljaju probleme koji su često prisutni kod pomagačkih profesija. To je prepoznato i u slučaju školskih pedagoga. Iako školski kontekst zahteva timsko delovanje svih aktera školskog života, posebno kada je reč o stručnim saradnicima čija priroda posla zahteva 
isprepletenost njihovih profesionalnih uloga i zadataka, ovakvo stanje može da ima za posledicu nedovoljno jasnu percepciju profesionalnog identiteta školskog pedagoga. Stoga je veoma važno intezivirati empirijska proučavanja ove tematike, jer dobijeni nalazi mogu pružiti odgovore na brojna pitanja - od analize opštih uslova za profesionalno razvijanje do razmatranja uticaja različitih ličnih, profesionalnih i kontekstualnih faktora koji utiču na izraženiji ili slabije izražen profesionalni identitet školskog pedagoga. Osim toga, takvi istraživački nalazi mogu da potpomognu pri oblikovanju radnog okruženja koje doprinosi efektivnijem i efikasnijem ostvarivanju profesionalnih uloga školskih pedagoga. S druge strane, $\mathrm{s}$ obzirom na to da se u razmatranju profesionalnog ideniteta apostrofira dinamična, kontinuriana i aktivna konstrukcija i rekonstrukcija, posvećivanje pažnje ovim pitanjima može da doprinese podizanju svesti o značaju kontinuiranog profesionalnog razvoja školskih pedagoga. Istovremeno, dobijeni nalazi mogu da implikuju i relevantne smernice za unapređenje inicijalnog obrazovanja pedagoga, što je od izuzetne važnosti za formiranje profesionalnog identiteta koje počinje upravo u periodu pripreme pojedinca za profesiju. Moguće je zaključiti da je ovo, kod nas prilično zanemareno, istraživačko polje, veoma važno za afirmaciju pozicije pedagoga u školi (a samim tim i za unapređenje statusa i pozicije koji on zauzima u društvu), čime se stvara dobra osnova za unapređenje kvaliteta obrazovno-vaspitnog procesa i bolje funkcionisanje škole u celini.

Senka Slijepčević, Slađana Zuković

THE IMPORTANCE OF STUDYING THE SCHOOL PEDAGOGUE'S PROFESSIONAL IDENTITY

\section{Summary}

Professional identity, its structure and characteristics have been a trending topic in social sciences research in the past twenty years. Special interest in this area of research lies in the so-called helping professions. The reason for this is the aspiration for improvement, development and affirmation of these professions. The framework for understanding and studying professional identity is social identity theory, according to which professional identity is part of a broader social identity that answers questions about the contribution and importance that an individual's professional activity has in the society and that is an integral part of the individual's self-concept. Professional identity represents that part of the self which is developed through fulfilling a person's professional role and includes professional knowledge and competencies, belief systems and professional values, professional motives and the social status of the profession/professional. In that sense, the profession of the pedagogue, which is also one of the helping professions, represents a very inspiring field for 
the study of the professional identity construct. Another reason why studying professional identity is relevant for pedagogy as a science is the fact that the pedagogue profession is relatively new and very dependable on changes in society. Accordingly, the structure of professional identity, its components, as well as the indicators that influence its development, depend largely on the context where the pedagogue performs his/her activities. Bearing in mind the specificity of the school context, this paper emphasizes the need to study numerous (both personal and contextual) factors that determine the development of the professional identity of a school pedagogue. The importance and necessity of conducting empirical research on this topic are particularly emphasized, as identifying factors that contribute to the development of a clear professional identity can represent a significant resource for enhancing pedagogues' practice and accordingly for improving the practice of the school as an institution.

Key words: professional identity, pedagogue, social identity theory, self-efficacy, selfesteem.

\section{LITERATURA}

Auxier, C. R., Hughes, F. R., \& Kline, W. B. (2003). Identity Development in counselors in-training. Counselor Education and Supervision, 43, 25-38.

Bandura, A. (1997). Self-efficacy. The exercise of control. New York: W.H. Freeman and Company.

Bandura, A. (1986). Social foundation of thought and action: A social cognitive theory. Englewood Cliffs, NJ: Prentice Hall

Beijaard, D., Meijer, P.C.\& Verloop, N. (2004). Reconsidering research on teachers' professional identity. Teaching and Teacher Education, 20, 107128.

Bergami, M. \& Bagozzi, R. P. (2000). Self-categorization, affective commitment and group self-esteem as distinct aspect of social identity in the organization. British journal of social psychology, 39 (4), 555-577.

Bodenhorn, N. \& Skaggs, G. (2005). Development of the school counselor Selfefficacy scale. Measurement and evaluation in counseling and development, 38 (1), 14-28.

Brown, R. (2003). Međugrupni odnosi. U: Hewstone, M. \& Stroebe, W. (Ur.) (2003). Uvod u socijalnu psihologiju. Europske perspektive. Zagreb: Naklada Slap. 427-458.

Brott, P. E. \& Myers, J. E. (1999). Development od professional school counselor identity. Professional school counseling, 2 (5), 339-348. 
Butler, S. K. \& Constantine, M. G. (2005). Collective Self-Esteem and Burnout in Professional School Counselors. Professional school counseling, 9 (1), 5562.

Cai, Z., Guan, Y., Li, H., Shi, W., Guo, K., Liu, Y., ...Hua, H. (2015). Self-esteem and proactive personality as predictor of future work self and career adaptability: An examination of mediating and moderating processes. Journal of vocational behaviour, 86, 86-94.

Chesnut, S. R. \& Burley, H. (2015). Self-efficacy as a predictor of commitment to the teaching profession: A meta-analysis. Educational research review, 15, $1-16$.

Chin Pei, T. (2014). Educating for professional identity development. (Doctoral dissertation). Retrieved from: https://repub.eur.nl/pub/77318/

Cooper, K., \& Olson, M. R. (1996). The multiple 'I's' of teacher identity. In: Kompf, M., Bond, W. R., Dworet, D. \& R. Boak T. (Eds.) (1996). Changing research and practice: Teachers' professionalism, identities and knowledge. London/Washington, DC: The Falmer Press. 78-89.

Ellemers, N., Kortekaas, P. \&Ouwerkerk, J. W. (1999). Self-categorisation, commitment to the group and group self-esteem as related but distinct aspects of social identity. EuropeanJournal of Social Psychology, 29 (2/3), 371-389.

Emerson, C. H. (2010). Counselor Professional identity: Construction and validation of the counselor professional identity measure. (Doctoral dissertation). Retrieved from: http://libres.uncg.edu/ir/uncg/f/emerson_ uncg_0154d_10396.pdf

Gibson, D.M., Dollarhide, C.T \& Moss, J.M. (2010). Professional identity development: A grounded theory of transformational tasks of new counselors. Conselor Education \& Supervision, 50 (1), 21-38.

Goodson, I. F., \& Cole, A. L. (1994). Exploring the teacher's professional knowledge: Constructing identity and community. Teacher Education Quarterly, 21(1), 85-105.

Hogg, M. A. \& Terry, D. J. (2001). Social identity theory and organizational processes. In: M. A. Hogg \& D. J. Terry (Eds.) Social identity processes in organizational context (pp. 1-12). USA Philadelphia: Psychology press.

Horowitz, I. A. \& Bordens, K. S. (1995). Social Psychology. USA California: Meyfield Publishing Company.

Ibarra, H. (1999). Provisional selves: experimenting with image and identity in professional adaptation. Administrative science quarterly, 44 (4), 764-791. 
Lamote, C. \& Engels, N. (2010). The development of student teacher' professional identity. European Journal of Teacher Education, 33 (1), 3-18.

Luke, M. \& Goodrich, K. M. (2010). Chi Sigma Iota chapter leadership and professional identity development in early career counselors. Counselor education \& supervision, 50 (1), 56-78.

Moore, M. \& Hofman, J. E. (1988). Professional identity in institution of higher learning in Israel. Higher education, 17 (1), 69-79.

Myers, D. G. (1996). Social psychology. New York: The McGraw-Hill Companies, Inc.

Myers, J. E., Sweeney. T. J., \& White, V. E. (2002). Advocacy for counseling and counselors: A professional imperative. Journal of Counseling \& development, 80 (4), 394-402

Pavlović Breneselović, D. (2013). Čemu služi pedagog. Priča u tri slike. U: Krnjaja, Ž., Pavlović Breneselović, D. i Popović, K. (ured.) (2013). Pedagog između teorije i prakse. Zbornik radova. Beograd: Filozofski fakultet i Pedagoško društvo Srbije. 18-26.

Popov, N. i Spasenović, V. (2018). Stručni saradnik u školi-Komparativni pregled za 12 zemalja. Sofija: Bugarsko društvo za komparativnu pedagogiju.

Pravilnik o programu svih oblika rada stručnih saradnika (2012). Sl. Glasnik RS, Prosvetni glasnik, br. 5/2012.

Pravilnik o standardima kvaliteta rada ustanove (2018). Sl. glasnik RS, - Prosvetni glasnik, br. 14/2018.

Puglia, B. (2008). The professional identity of counseling students in master's level CACREP accredited programs. (Doctoral dissertation). Retrieved from: ProQuest. (UMI No. 3324071).

Purkey, W. (1988). An overview of self-concept theory for counselors. ERIC Clearinghouse on Counseling and Personnel Services, Ann Arbor, Mich. (AnERIC/CAPS Digest: ED304630).

Rodgers, C. \& Scott, K. (2008). The development of the personal self and professional identity in learning to teach. In: Cochran-Smith, M., FeimanNemser, S., McIntyre, D. J. \& Demers, K. E. (Eds.) (2008). Handbook of research on teacher education: Enduring questions and changing contexts. New York: Routledge. 732-755.

Skorikov, V. B. \& Vondracek, F. W. (2011). Occupational identity. In: Schwartz S. J., Luyckx K., \& Vignoles, V. L. (Eds.) (2011). Handbook of identity theory and research. New York, NY: Springer. 693-714. 
Spasenović, V. i Hebib E. (2014).Kako inicijalno obrazovanje i zahtevi prakse doprinose izgradnji profesionalnog identiteta pedagoga. U: Matović, N., Spasenović, V. I Antonijević, R. (ured.) (2014). Identitet profesije pedagog u savremenom obrazovanju. Beograd: Filozofski fakultet. 2-7.

Staničić, S. (2017). Profesionalni pogled na prošle, sadašnje i buduće izazove u radu (školskog) pedagoga: homage vlastitoj profesiji. U: Turk, M. (ured.) (2017). Suvremeni izazovi u radu (školskog) pedagoga. Zbornik u čast Stjepana Staničića. Rijeka: Filozofski fakultet u Rijeci. 67-77.

Šućur, Z. (2011). Kako socijalni pedagozi u hrvatskoj vide društveni i profesionalni status vlastite struke? U: Poldrugač Z., Bouillet D. i Ricijaš, N. (ured.) (2011). Socijalna pedagogija znanost, profesija i praksa u Hrvatskoj. Zagreb: Sveučilište u Zagrebu. 209-228.

Tajfel, H. (1982). Social psychology of intergroup relations. Annual review of psychology, 33 (1), 1-39.

Trnavac, N. (1996). Pedagog u školi. Beograd: Učiteljski fakultet u Beogradu Centar za usavršavanje rukovodilaca u obrazovanju.

Vacc, N. A. \& Loesch, L. C. (1987). Counseling as a profession. Indiana USA: Accelerated development INC.

Wang, H., Hall N. C. \& Rahimi, S. (2015). Self-efficacy and causal attributions in teachers: Effects on burnout, job satisfaction, illness, and quitting intentions. Teaching and teacher education, 47, 120-130.

Watts. R. (1987). Development of professional identity in Black clinical psychology students. Professional Psychology: Research and practice, 18 (1), 28-35.

Woo, H. (2013). Instrument construction and initial validation: professional identity scale in counseling (PISC). (Doctoral dissertation). Retrieved from: https://ir.uiowa.edu/etd/2663/

Woo, H., Lu, J. \& Bang, N. (2018). Professional identity scale in counseling (PISC): revision of factor structure and psychometrics. Journal of counselor leadership and advocacy, 5 (2), 137-152.

Zakon o osnovama sistema obrazovanja i vaspitanja (2017). Sl. glasnik RS, br. $88 / 2017$

Živković, P. i Ranđelković, D. (2013). Korelati profesionalnog identiteta nastavnika. Teme, 37 (2), 647-666. 